\title{
APLIKASI PENGENALAN HURUF HIJAIYAH UNTUK ANAK USIA DINI BERBASIS ANDROID MENGGUNAKAN AUGMENTED REALITY (AR)
}

\author{
${ }^{1}$ Alwiyah Faridah, ${ }^{2}$ Muhammad Imron Rosadi \\ 1,2Teknik Inofrmatika, Universitas Yudharta Pasuruan. \\ 1,2Pasuruan, JawaTimur 67162 \\ 1alyaalwiyah458@gmail.com, 2imron.rosadi@yudharta.ac.id
}

\begin{abstract}
ABSTRAK
Smartphone kerap digunakan untuk mengendalikan aplikasi mobile sebagai sarana untuk mengakses dan mengolah informasi. Penggunaan smartphone banyak diminati mulai dari kalangan dewasa maupun anak-anak. Didalam smartphone terdapat ratusan aplikasi yang paling menarik yaitu game. Pada awalnya game ditunjukkan sebagai media penghilang kejenuhan saat belajar, namun fitur yang satu ini tidak jarang membuat anak jadi lupa waktu, sehingga menyebabkan anak-anak kelelahan dan malas untuk belajar. Bentuk kemajuan teknologi yang bisa dimanfaatkan dalam bidang pendidikan adalah Augmented Reality yaitu sebuah terobosan di dunia multimedia dan pengolahan citra digital yang sedang maju. Aplikasi tersebut digunakan untuk pengenalan huruf hijaiyah bagi anak dini berbasis android. Pembuatan aplikasi ini menggunakan software Unity 3D untuk marker huruf-huruf hijaiyah dan Vuforia. Pada impelementasi akan ada proses scanning untuk memunculkan efek 3D dari huruf-huruf hijaiyah tersebut. Tujuan dari penelitian ini menerapkan Augmented Reality pada smartphone untuk mengurangi bermain game dan menyeimbangkan minat belajar huruf hijaiyah sejak dini. Hasil penelitian yang dilakukan menunjukkan bahwa metode tersebut menghasilkan minat belajar terhadap anak-anak lebih baik.
\end{abstract}

Kata kunci : Smartphone, Augmented Reality, Unity 3D, Vuforia.

\section{ABSTRACT}

Smartphones are often used to control mobile applications as a means to access and process information. The use of smartphones is in great demand ranging from adults and children. In smartphones

there are hundreds of the most interesting applications, games. At first the game was shown as a media to relieve boredom while learning, but this one feature not infrequently makes children forget time, thus causing children to be tired and lazy to learn. The form of technological advancements that can be utilized in the field of education is Augmented Reality which is a breakthrough in the world of multimedia and digital image processing that is advancing. The application is used for the introduction of hijaiyah letters for android-based early childhood. The making of this application uses Unity 3D software for marker hijaiyah letters and Vuforia. In implementation there will be a scanning process to bring up the $3 D$ effect of the hijaiyah letters. The purpose of this study is the application of Augmented Reality on smartphones to reduce playing games and balance interest in learning hijaiyah letters early on. The results of research conducted indicate that the method produces better interest in learning for children.

Keywords: Smartphone, Augmented Reality, Unity 3D, Vuforia. 


\section{PENDAHULUAN}

\subsection{Latar Belakang}

Pesatnya kemajuan teknologi pada telepon seluler yang sekarang tidak hanya digunakan sebagai media komunikasi tapi sudah menjadi smartphone bisa di gunakan sebagai media informasi, belajar, hiburan dan sebagainya. Kebutuhan terhadap telepon selular telah menjadi kebutuhan primer tergantung akan kebutuhan pengguna itu sendri. Salah satunya yang kerap digunakan saat ini adalah untuk mengendalikan aplikasi mobile sebagai sarana untuk mengakses dan mengolah informasi. Informasi yang dicantumkan dalam buku yang menjadi panduan dalam proses pembelajaran mulai tergantikan dengan media digital (Afriansyah, 2018).

Saat ini pengguna smartphone tidak hanya kalangan dewasa saja, tetapi anak-anak juga meminati gadget jenis ini. Bagi anak kecil, apliksai yang paling menarik adalah game. Meskipun pada awalnya game ditunjukkan sebagai media penghilang kejenuhan saat belajar, namun fitur yang satu ini tidak jarang membuat anak jadi lupa waktu. Seperti yang dilansir oleh kompas, bahwasannya anak-anak yang kecanduan game cenderung bersikap agresif, tidak bertanggung jawab, tidak realistis dan kurang focus dan otak serebral mereka jadi kurang produktif dan kreatif (Huda, 2013).

Android merupakan sistem operasi yang diluncurkan oleh Google khususnya bagi smartphone dan tablet. Penggunaan Informasi dan Teknologi Komunikasi memunculkan suasana yang menggembirakan dalam proses pembelajaran, karena memuat gambar, video dan suara yang timbul sehingga membuat anak-anak tidak mudah jenuh dan dapat memacu pembelajaran pada anak usia dini. (Imaduddin \& Permana, 2017).

Mempelajari huruf hijaiyah merupakan proses awal agar bisa membaca kitab suci Al-Qur'an. Untuk menambah keahlian membaca huruf hijaiyah pada anak sungguh diperlukan pemilihan media pembelajaran yang sesuai dan pendekatan yang baik, karena mempunyai peranan yang sangat penting dalam proses belajar. Pembelajaran huruf hijaiyah lebih sulit karena huruf hijaiyah merupakan huruf yang jarang digunakan untuk bahasa sehari-hari. Agar anak tidak merasa bosan dan lebih bersemangat dalam belajar. Guru menerapkan pembelajaran aktif learning.

Kebanyakan anak usia prasekolah sangat aktif bermain, dalam memberikan pola asuh atau metode belajar kepada anak usia prasekolah dibutuhkan suatu pembelajaran yang interaktif berupa audio visual agar anak cenderung lebih cepat tanggap, salah satu faktor pendukung pembelajaran yang interaktif adalah dengan adanya media atau fasilitas belajar yang menggunakan teknologi mobile-learning (M-learning). Lebih seringnya anak-anak menghabiskan waktu untuk bermain handphone dari pada membaca buku membuat orang tua yang mendidik anaknya membaca dan menulis dengan bersandar pada buku dan poster menjadi kurang menarik keinginan anak untuk belajar karena merasa terlalu monoton. Dari permasalahan tersebut, penelitian kali ini penulis ingin membuat sebuah aplikasi pembelajaran berbasis android dengan menggunakan media smartphone.

Berdasarkan latar belakang tersebut maka penelitian ini diwujudkan sebagai bahan penyusun skripsi dengan judul : "APLIKASI PENGENALAN HURUF HIJAIYAH UNTUK ANAK USIA DINI BERBASIS ANDROID MENGGUNAKAN AUGMENTED REALITY (AR)”.

\section{METODE PENELITIAN}

\subsection{Metodologi Penelitian}

Penelitian ini menggunakan metode waterfall dalam pembuatan aplikasi android game edukasi ini dengan fitur notifikasi. Pengerjaan aplikasi akan dilakukan secara bertahap. Tahapannya adalah analisis, desain, kode, dan test. 


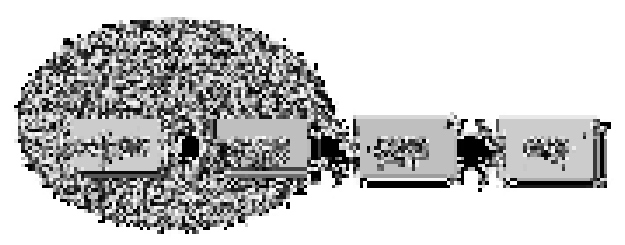

Gambar 2.1 Tahapan Metode Waterfall

\subsection{Use case Diagram}

Use case diagram digunakan untuk menggambarkan fitur-fitur yang dapat dijalankan pada aplikasi. Dapat diartikan sebagai rangkaian atau uraian sekelompok yang saling terkait dan membentuk sistem secara teratur yang dilakukan atau diawasi oleh sebuah aktor.

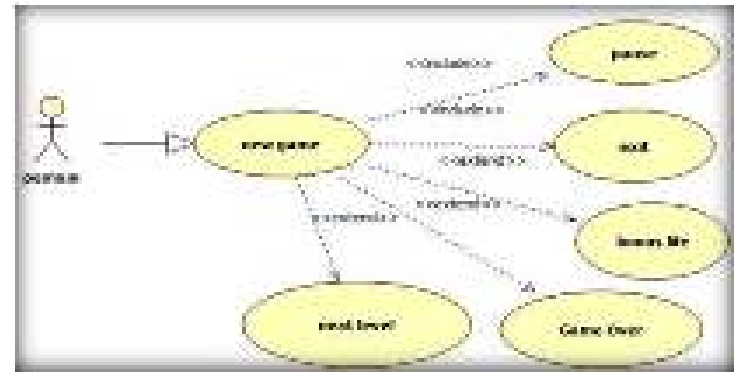

Gambar 2.2 Use case Diagram

\subsection{Flowchart}

Gambaran dalam bentuk diagram alir dari algoritma-algoritma dalam suatu program. Bagian ini merupakan proses untuk memasukkan data ke komputer melalui device yang ada. Diagram alir dari sistem yang akan penulis bangun adalah sebagai berikut:

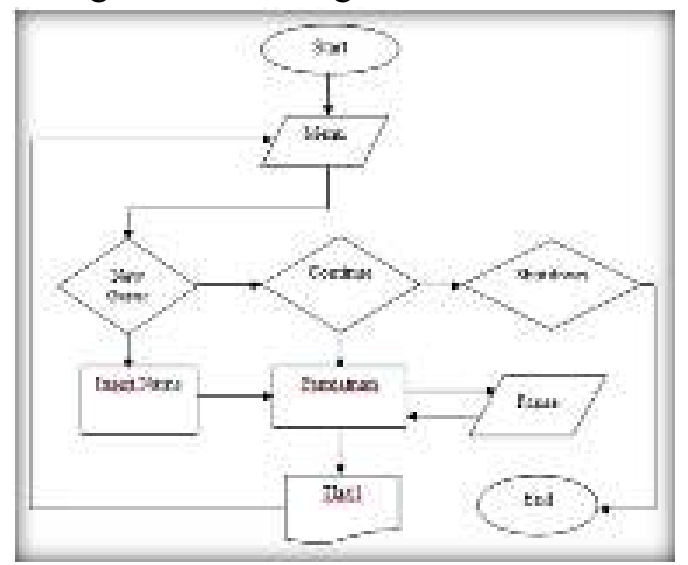

Gambar 2.3 Flowchart

\subsection{Desain 3D Huruf Hijaiyah}

Desain 3D huruf hijaiyah yang dimaksud disini adalah membuat gambar dalam bentuk 3D yang berguna untuk menampilkan gambar 3D pada android ketika marker (target gambar) terdeteksi dengan benar.

Adapun desain 3D untuk membuat huruf hijaiyah pada penelitian ini menggunakan aplikasi blender-2.79b. berikut ini adalah layout contoh desain 3D huruf hijaiyah . 


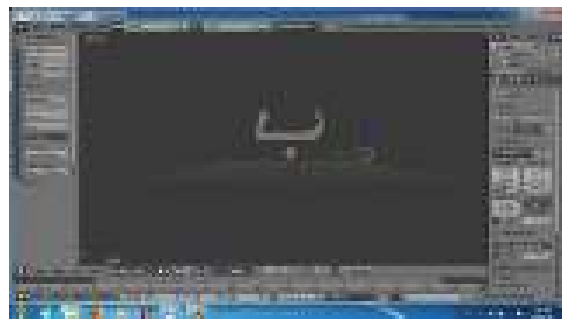

Gambar 2.4 Blender

\subsection{Pembuatan Marker}

Dalam membuat marker yang akan digunakan, maka akan diperlukan sebuah file gambar yang berformat JPG dan gambar tersebut akan diupload ke database vuforia. Marker yang akan dibuat bernama image target. Image target adalah gambar yang dapat di deteksi dan dilacak oleh vuforia SDK. Jenis gambar tidak seperti marker tradisional seperti data matrix code dan QR codes, marker juga tidak perlu warna hitam dan putih yang berdesain khusu untuk dikenali.

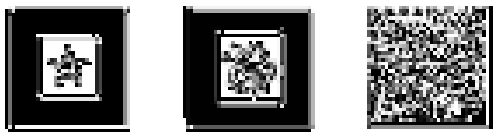

Gambar 2.5 marker tradisonal

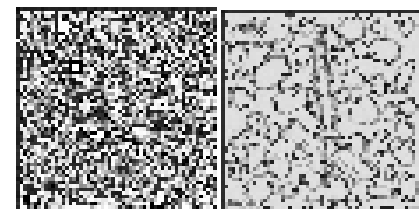

Gambar 2.6 marker non tradisional

Marker atau juga disebut image target merupakan gambar yang digunakan sebagai target utama dalam memunculkan Augmented Reality. Merker akan diproses pada Unity 3D dan dibuat menggunakan sebuah gambar.

\subsection{Upload Marker Ke Vuforia}

Image hasil editan yang sudah dilakukan di blender akan diupload ke website vuvoria. File yang telah diupload tersebutakan dinilai kualitasnya oleh sistem. Semua marker yan telah di upload akan menghasilkan sebuah source code (hasil dari gambar setelah digenerate vuforia) berupa file $x m l$. File $x m l$ ini merupakan file konfigurasi dari vuforia terhadap marker-marker yang telah diupload. Langkah-langkah pembuatan marker lengkapnya seperti berikut ini :

1. Masuk ke website vuforia : www.developer.vuforia.com

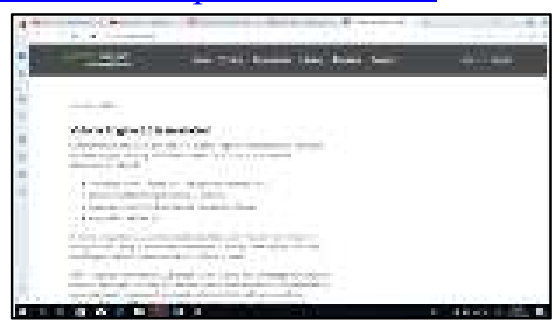

Gambar 2.7 website vuforia

2. Login terlebih dahulu 


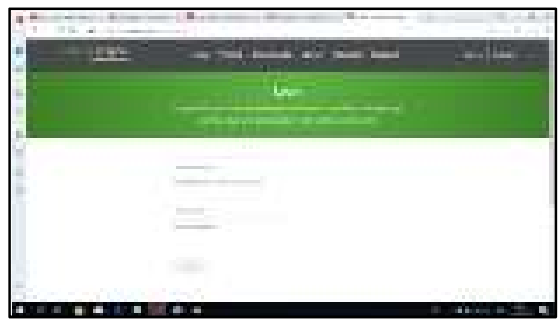

Gambar 2.8 login vuforia

Sebelum login ke vuforia pastikan anda sudah memiliki akun vuforia terlebih dahulu.

3. Setelah berhasil login pilih menu develop lalu klik sub menu target manager

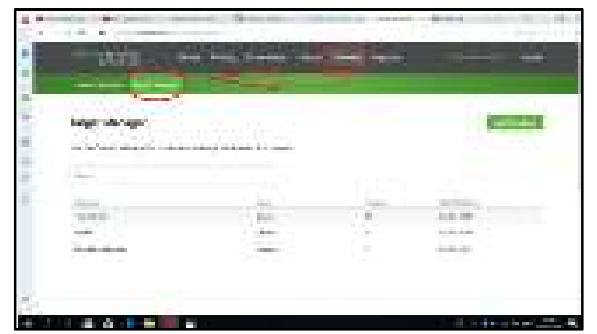

Gambar 2.9 dashboard user

4. Setelah itu klik Add Database untuk mengupload marker

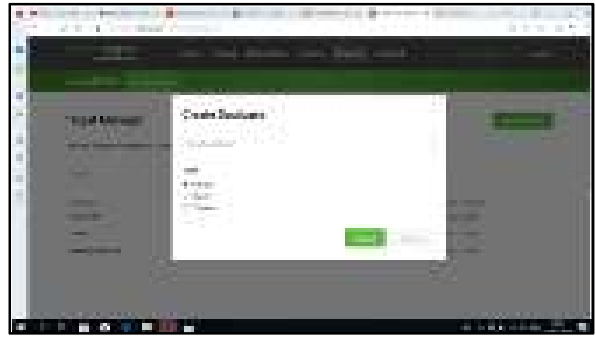

Gambar 2.10 create database

5. Hasil upload marker

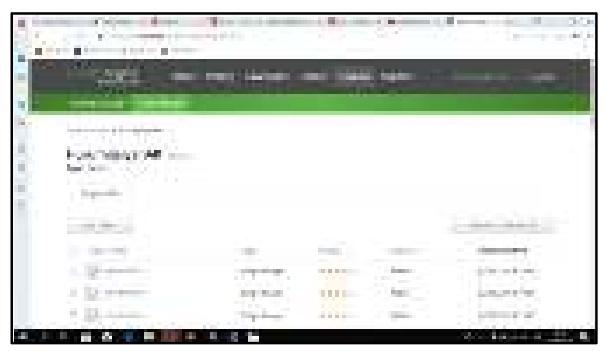

Gambar 2.11 upload marker

Bintang pada kolom ranking menentukan kualitas gambar yang digunakan sebagai marker.

6. Download marker dari vuforia

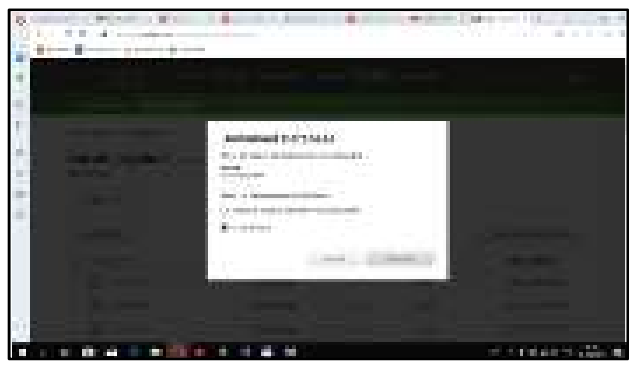

Gambar 2.12 download marker 
Marker yang sudah diupload ke vuforia selanjutnya akan didownload dan akan di impor ke unity.

7. Impor marker ke Unity

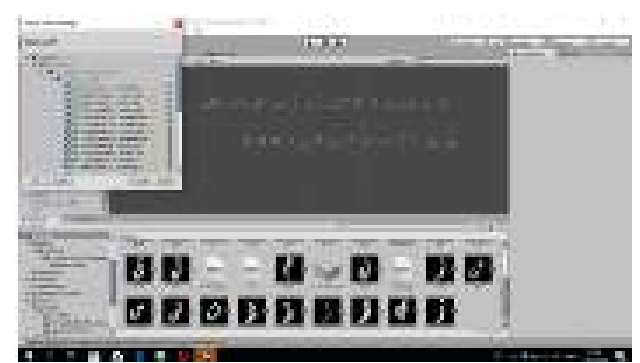

Gambar 2.13 impor marker ke unity

Selanjutnya marker yang sudah didownload akan di impor ke unity untuk di ekstrak.

\section{HASIL DAN PEMBAHASAN}

\subsection{Cara Penggunaan Aplikasi}

Disini akan dijelaskan langkah-langkah mulai dari penginstalan dan cara menggunakan aplikasi pengenalan huruf hijaiyah. Langkah-lankgkahnya sebagai berikut :

1. Buka pengelola file untuk menginstal aplikasi

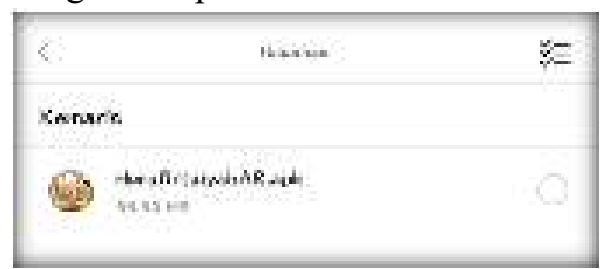

Gambar 3.14 icon aplikasi

2. Instal aplikasi pengenalan huruf hijaiyah si smartphone android dan tunggu hingga proses penginstalan selesai.

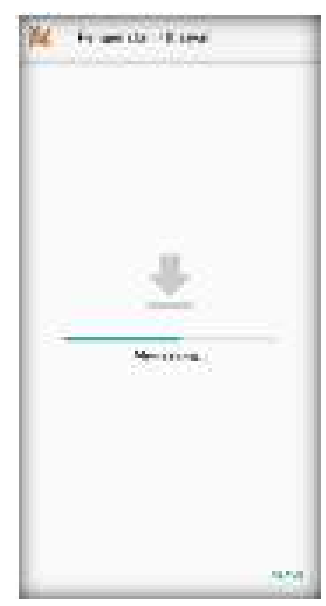

Gambar 3.15 Proses instalasi aplikasi

3. Jalankan aplikasi yang telah terinstal di smartphone dan akan mundul splashscreen seperti ini. 


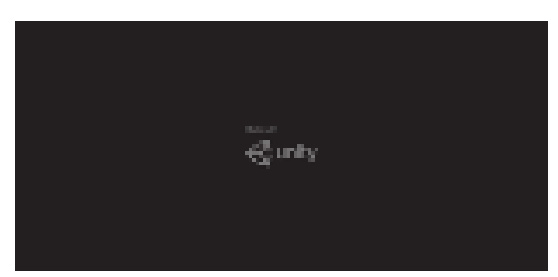

Gambar 3.16 awal aplikasi

4. Tampil menu utama aplikasi pengenalan huruf hijaiyah.

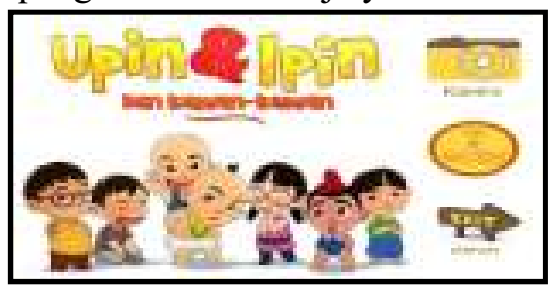

Gambar 3.17 menu utama aplikasi

Tampilan menu utama memiliki tiga tombol yaitu tombol mulai kamera, kuis, dan keluar. Ketika tombol mulai diklik, akan mengakses kamera android dan menampilkan desain huruf hijaiyah berbentuk 3D pada marker yang sudah didefinisikan. Aplikasi akan mendeteksi marker satu persatu dan tidak akan menampilkan desain 3D apabila tidak diarahkan ke marker dengan tepat.

5. Klik tombol kamera dan arahkan kamera ke marker yang telah disiapkan.

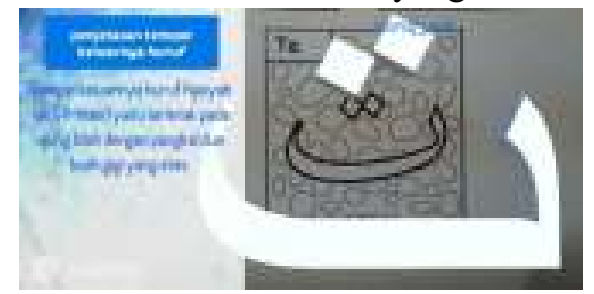

Gambar 3.18 deteksi marker aplikasi

6. Klik tombol kuis untuk bermain kuis pilihan ganda
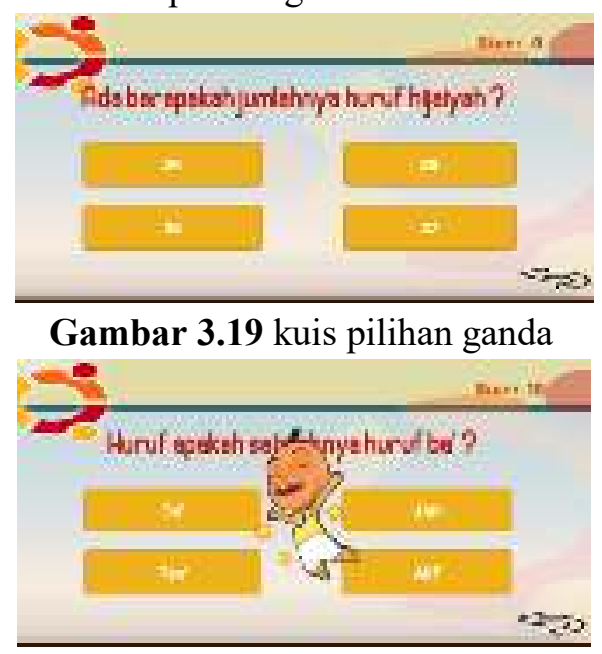

Gambar 3.20 kuis benar 
Vol. 11 No. 2 - Desember 2019 p-ISSN 2086-3489 (Print)- e-ISSN 2549-354X (Online)

Avaiable online at http://jurnal.yudharta.ac.id/v2/index.php/EXPLORE-IT/

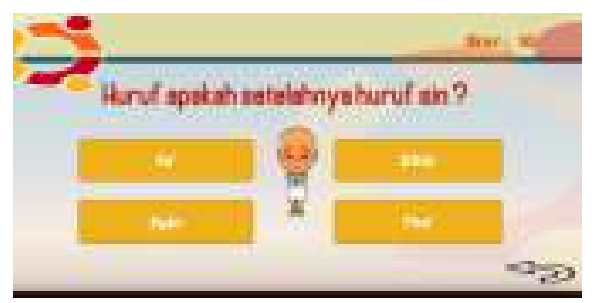

\section{Gambar 3.21 kuis salah}

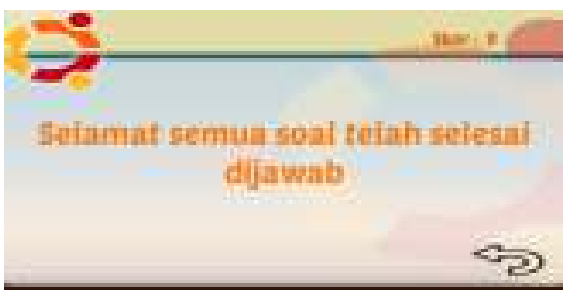

Gambar 3.22 kuis selesai

\subsection{Pengujian aplikasi}

Pengujian aplikasi ini menggunakan teknik pengujian black box. Dimana pada tahap ini akan menguji fungsionalitas dari fitur-fitur yang disediakan aplikasi.

Tabel 3.1 Tabel pengujian fungsionalitas

\begin{tabular}{|c|c|c|c|c|}
\hline No. & 7engujas & $\begin{array}{l}\text { Hast yase } \\
\text { tihernoken }\end{array}$ & $\begin{array}{c}\text { Itasil } \\
\text { pesgojian }\end{array}$ & kesimputan \\
\hline t & $\begin{array}{l}\text { SarA NPE } \\
\text { QSuna) }\end{array}$ & 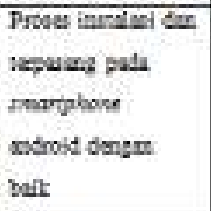 & $\begin{array}{l}\text { Seras } \\
\text { hasple }\end{array}$ & valt \\
\hline 2 & 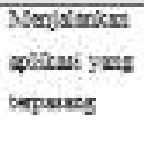 & 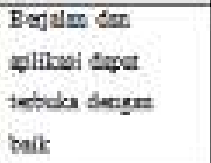 & $\begin{array}{l}\text { Serval } \\
\text { herper }\end{array}$ & vald \\
\hline 3 & 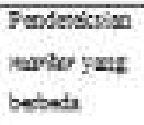 & 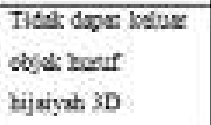 & $\begin{array}{l}\text { Serval } \\
\text { harpen }\end{array}$ & Void \\
\hline 7 & 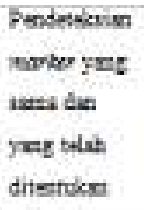 & 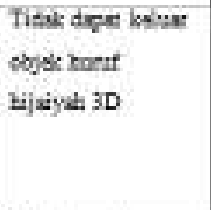 & $\begin{array}{l}\text { hadk } \\
\text { setus } \\
\text { herquit }\end{array}$ & Invalis \\
\hline 5 & $\begin{array}{l}\text { Tonbel } \\
\text { melei ditiok }\end{array}$ & 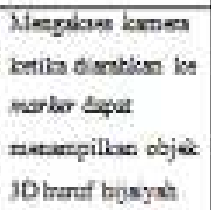 & $\begin{array}{l}\text { Sevala } \\
\text { harpon }\end{array}$ & Valid \\
\hline 8 & $\begin{array}{l}\text { Toebolind } \\
\text { dines: }\end{array}$ & $\begin{array}{l}\text { Trapu beberma } \\
\text { bus pilihn zroda }\end{array}$ & $\begin{array}{l}\text { Serval } \\
\text { berpen }\end{array}$ & vald \\
\hline 7 & $\begin{array}{l}\text { Toubd } \\
\text { keued diase }\end{array}$ & Koluz ąlikwi & $\begin{array}{l}\text { Sevele } \\
\text { besput }\end{array}$ & Fabs \\
\hline
\end{tabular}

\subsection{Pengujian berdasarkan spesifikasi smartphone}

Berikut ini adalah daftar smartphone yang telah diinstal aplikasi pengenalan huruf hijaiyah yang digunakan untuk menguji aplikasi. 
Tabel 3.2 Perangkat penguji aplikasi

\begin{tabular}{|c|c|c|}
\hline Peranglas I & Peranghat 2 & Peranglat 3 \\
\hline 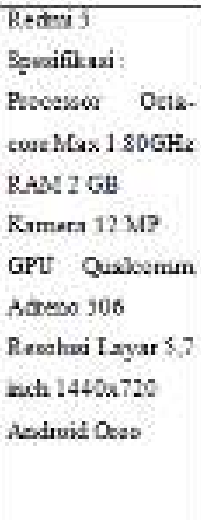 & 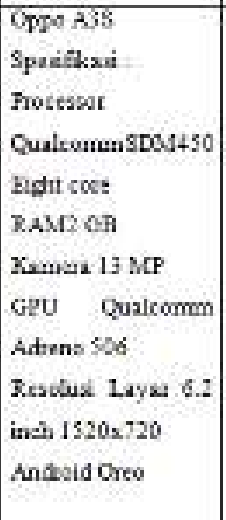 & 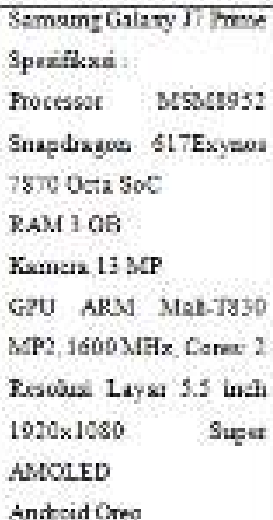 \\
\hline
\end{tabular}

Pada gambar diatas merupakan hasil pengujian respon time loading kamera smartphone. Pada pengujian ini dapat disimpulkan bahwa semakin tinggi spesifikasi device smartphone terutama pada RAM dan processor maka loading pada kamera dalam aplikasi akan berjalan lebih cepat.

Tabel 3.3 pengujian respon time aplikasi

\begin{tabular}{|c|c|c|c|c|}
\hline \multirow{2}{*}{ So. } & \multirow{2}{*}{ Pross } & \multicolumn{3}{|c|}{ Hespen 7 ime (s) } \\
\hline & & Peratekat 1 & Peranglien 2 & Perragkat 3 \\
\hline 1 & 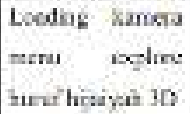 & 5 & 5 & $r$ \\
\hline
\end{tabular}

Berdasarkan gambar diatas dapat disimpulkan bahwa perangkat 1 mampu mendeteksi marker membutuhkan waktu 5 detik, perangkat 2 membutuhkan waktu 5 detik, dan perangkat 3 membutuhkan waktu 3 detik.

\subsection{Kesimpulan}

\section{PENUTUP}

1. Hasil pengujian fungsionalitas dan pengujian jarak aplikasi pengenalan huruf hijaiyah berjalan dengan baik.

2. Aplikasi ini memiliki persentase kelayakan sebesar $85 \%$, perhitungan ini didapatkan dari perhitungan Likert yang dilakukan kepada 16 responden. Dapat disimpulkan bahwa kualitas aplikasi AR pengenalan huruf hijaiyah memiliki kategori "Layak".

3. Aplikasi ini menampilkan desain obyek 3D huruf-huruf hijaiyah. 


\subsection{Saran}

1. Perlu diujicoba berdasarka kemiringan objek

2. Responden prlu ditambhankan untuk menguji akurasi lebih baik.

\section{DAFTAR PUSTAKA}

[1] Afriansyah Aidil. 2018. Aplikasi tuntunan doa-doa harian umat muslim berbasis android. Program studi teknik informatika, Politeknik Sekayu.

[2] Alfian Mukhammad. 2017. Implementasi Metode Klasifikasi Bayesian Untuk Strategi Menyerang NPC pada Game Pembelajaran Menghafal Al-qur'an.

[3] Falah Muhammad Zidnal. 2016. Aplikasi Game Puzzle Al-qur'an Juz 30 Untuk Meningkatkan Hafalan Juz'amma Berbasis Android Di Ponpes Al-Muhsinin.

[4] Huda M. Miftahul. 2013. Game satri story untuk pengenalan huruf hijaiyah menggunakan metode $M C R N-G e n e r a t o r$. Universitas Islam Negeri (UIN) Maulana Malik Ibrahim Malang.

[5] Kurniawan, Herman. Pendukung Materi Taman Pendidikan Al-qur'an Melalui Game Edukasi Untuk Anak Umur 6-10 Tahun Menggunakan Macromedia Flash 8. Universitas Muhammadiyah Surakarta.

[6] Mustaqim Ilmawan.2016. Pemanfaatan Augmented Reality sebagai media pembelajaran. Fakultas teknik, Universitas Negeri Yogyakarta.

[7] Nugroho Atmoko, Pramono Basworo Ardi. 2017. Aplikasi mobile augmented reality berbasis vuforia dan unity pada pengenalan objek 3D dengan studi kasus gedun $\mathrm{M}$ universitas semarang.

[8] Putri Rahayu. 2015. Rancang Bangun Aplikasi Mobile Pembelajaran Doa Islami Menggunakan Augmented Reality. Universitas Islam Negeri Maulana Malik Ibrahim Malang.

[9] Saurina Nia. Pengembangan media pembelajaran untuk anak usia dini menggunakan Augmented Reality. Jl.Dukuh Kupang XXV/54,Surabaya.

[10] Cahya Yuda I.A. 2013. Aplikasi game route-puzzle (labirin) secara 3D (dimensi) menggunakan Blender. Universitas Muhammadiyah

Surakarta 
JURNAL EXPLORE IT!

Vol. 11 No. 2 - Desember 2019

p-ISSN 2086-3489 (Print)- e-ISSN 2549-354X (Online)

Avaiable online at

http://jurnal.yudharta.ac.id/v2/index.php/EXPLORE-IT/ 